\title{
A Dissertação de Mestrado: um Estudo sobre as Interações entre o Orientador e o Orientando com Base em Incidentes Críticos
}

Pesquisadores: José Florêncio Rodrigues Jr., Denise de Souza Fleith e Kleide Márcia Barbosa Alves

Instituição: Universidade de Brasília

Fonte financiadora: Instituto Nacional de Estudos e Pesquisas Educacionais (INEP)

A dissertação é um requisito decisivo na obtenção do grau de mestre. Sua importância dentro do panorama da pós-graduação no Brasil, bem como a escassez da literatura sobre o tema, foram fatores que justificaram a realização deste estudo. Pretendeu-se com ele identificar circunstâncias que podem intervir no processo de elaboração de uma dissertação de mestrado.

$\mathrm{O}$ estudo concentrou-se nas figu- ras do orientador e do orientando. Baseou examinar as interações que ocorrem entre este e aquele durante o transcurso do projeto de dissertação. Trata-se de um estudo exploratório que baseou respostas para perguntas tais como: E possível identificar categorias nas referidas interações? Caso afirmativo, que categorias de interações propiciam o sucesso da dissertação? E que categorias de interações a estorvam ou inibem? 
Metodologia

Foram entrevistados 20 orientadores e 20 orientandos das áreas Ciências de Exatas e Humanas, oriundos da Universidade de Brasília. O tempo médio para a realização da dissertação em ambas as áreas foi de três semestres.

A Técnica do Incidente Crítico, proposta por Flanagan (1954) tem sido amplamente usada na pesquisa nas Ciências Sociais. Ela busca coletar impressões marcantes de conteúdo positivo (agradável) e negativo (desagradável) com vistas à identificação de perfis ou variáveis pertinentes a uma dada função ou fenômeno. Fundamental a essa técnica é que se obtenham relatos de ocorrências reais e não opiniões ou especulações sobre o fenômeno ou função em estudo.

Análise dos dados

INCIDENTES CRÍTICOS POSITIVOS E NEGATIVOS: A VISÃo DOS MESTRANDOS

Os mestrandos da área de Humanas relataram 17 incidentes críticos positivos e os da área de Exatas 16 incidentes, distribuídos em 5 categorias, a saber: 1 . Processo de Orientação Acadêmica, subdividida em Conteúdo e Gerenciamento; 2. Demonstração de Interesse por Parte do Orientador, subdividida em Início, Durante e Final do processo de orientação; 3. Relação Orientador/Orientando; 4. Características do Orientador e 5. Características do Orientando.

Com respeito aos aspectos negativos, os sujeitos da área de Humanas relataram 11 episódios e os da área de Exatas 14 episódios, distribuídos em 5 categorias, a saber: 1. Processo de Orientação Acadêmica; 2. Relação Orientador/Orientando; 3. Disponibilidade por Parte do Orientador; 4. Aspectos Relativos ao Tema da Dissertação e 5 . Características do Orientador.

Observou-se que os sujeitos do primeiro grupo atribuíram as dificuldades de condução da dissertação a aspectos de conteúdo e de como este é "trabalhado" pelo orientador durante o processo de orientação. Em contrapartida, os sujeitos da área de Humanas atribuíram a si dificuldades no desenvolvimento da dissertação, sem responsabilizar o 
orientador. Tampouco relataram muitos episódios com relação ao conteúdo, o que pareceu indicar que as dificuldades se encontravam mais no plano da definição prévia de objetivos de trabalho por parte do orientando.

Com respeito aos incidentes críticos positivos, os mais destacados estavam associados ao interesse por parte do orientador, principalmente no final do processo de orientação, próximo ao período de defesa da dissertação, especialmente pelos sujeitos da área de Humanas. Por outro lado, os sujeitos da área de Exatas registraram grande número de incidentes positivos com relação ao processo de orientação acadêmica, mais uma vez indicando sua preocupação com o objeto de estudo. A relação orientador/orientando foi ressaltada pelos dois grupos, e os aspectos mais mencionados foram a autonomia e liberdade que o orientando teve para desenvolver o seu trabalho.

INCIDENTES CRÍTICOS POSITIVOS E NEGATIVOS: A VISÃO DOS PROFESSORES

Os professores da área de $\mathrm{Hu}-$ manas relataram 28 incidentes positivos e os da área de Exatas, 20, distribuídos em cinco categorias, a saber: 1. Gerenciamento por Parte do Orientador; 2. Características de Personalidade do Orientando; 3. Gerenciamento por Parte do Orientando; 4. Aspectos Relativos ao Tema da Dissertação e 5. Aspectos ligados à Relação Orientador/Orientando. Esta categoria surgiu apenas nos dados referentes aos professores orientadores da área de Ciências Humanas.

Com relação aos incidentes críticos negativos, os professores da área de Humanas relataram 12 incidentes e os da área de Exatas 13 episódios, distribuídos em 6 categorias, a saber: 1 . Gerenciamento por Parte do Orientando; 2. Características Intelectuais e de Personalidade do Orientando; 3. Envolvimento Insuficiente do Mestrando com as Atividades Acadêmicas; 4. Gerenciamento por Parte do Professor Orientador; 5. Aspectos Relativos ao Tema da Dissertação e 6 . Aspectos Institucionais.

Com relação aos incidentes negativos, observou-se que estes, na maioria das vezes, diziam respeito 
à figura do orientando, ou seja, o insucesso no processo de elaboração da dissertação estava associado ao gerenciamento inadequado do curso por parte do mestrando (tais como falta de empenho na realização do trabalho e de contato com o orientador), às limitações intelectuais, à falta de autonomia e ao envolvimento limitado nas atividades acadêmicas.

Com relação aos incidentes positivos relatados pelos orientadores, observa-se que estão relacionados, de forma eqüitativa, ao desempenho de professores e alunos, ou seja, atribuindo-se o sucesso no processo de orientação tanto à atuação deles enquanto orientadores, como à dos orientandos. Este fato não se configura no relato dos orientandos, que, por sua vez, privilegiaram o desempenho do professor orientador enquanto gerente do processo de orientação, mas salientaram que o aluno tem um compromisso com a condução do seu mestrado.

Um outro aspecto muito destacado pelos orientadores diz res- peito as características de personalidade do orientando (tais como disciplina, iniciativa e autonomia), ponto este pouco considerado pelos alunos. Aspectos relativos ao conteúdo da dissertação foram igualmente ressaltados pelos dois grupos de professores.

Com relação aos incidentes negativos, para os professores, $o$ insucesso estava associado ao orientando. Para os alunos, o insucesso originou-se da incapacidade de o professor gerenciar o processo, ao domínio superficial por parte do orientador de aspectos do conteúdo, além da não disponibilidade do professor. Observou-se que o sucesso ou a frustração no processo de orientação é atribuído ao membro oposto da relação.

Os dados evidenciaram aspectos da interação no processo de elaboração da dissertação, os quais permitem a formulação de pressupostos básicos desta interação e de um modelo configurativo da interação orientador/orientando. 